\title{
Finite Element Analysis of Vibration and Noise of Scraper Conveyor
}

\author{
Liran XU \& Yu SU * \\ College of Materials Engineering, Shanghai University of Engineering Science, Shanghai 201620, China
}

Hanwu LIU

School of Mechanical-Electrical Engineering, North China Institute of Science and Technology, Langfang

065201, China

\begin{abstract}
The noise pollution produced by the scraper conveyor affects the working environment seriously. Based on a certain type of the scraper conveyor transmission system as a research object, using the finite element analysis software ANSYS for modal analysis, the results suggested that the natural frequencies of scraper and chute were the same in the $15^{\text {th }}$ order. This indicated that the resonance of scraper and chute in the $15^{\text {th }}$ order was the main cause of vibration noise. According to the above analysis results, an improvement scheme was put forward and then a modal analysis was done to verify its validity. Results indicated that the dynamic rigidity of chute was improved as well as the order of resonance, and the strain values of chute were decreased. The vibration noise would be reduced obviously. In the design process of mechanical equipment, this method for vibration noise test of mutual coupling components could provide an efficient method to reduce vibration noise.
\end{abstract}

KEYWORD: Scraper conveyor; Vibration and Noise; Modal Analysis; Finite Element; Natural Frequency

\section{INTRODUCTION}

Noise is listed as one of the three major pollutant sources in the world today (TIAN, H.T. 2008). To control the noise pollution and improve people's living standard and working environment, all countries had invested a lot of resources to reduce the vibration noise and had formulated a series of standards and regulations. Great progresses had been completed. With the greater development of society, more attentions have been paid on occupational safety, the safety of coal miners has been guaranteed. Improving the poor working environment of coal miners has become the next urgent problem. The present coal mining equipment is developing towards the large-scale and automated direction. The increasing outputs of coal mining make the load of coal machines bigger and bigger. The noise pollution caused by the mechanical vibration is more and more serious. Noise pollution has already become the main factor that influencing the working environment of coal miners (LIU, G.L. et al. 2011).

Scraper conveyor is a kind of continuous action type transport machinery with a flexible body as the traction mechanism, which is mainly used in the coal face or other places. For the particularity of its structure and working environment, the scraper conveyor has many advantages. So the scraper conveyer has been the only transportation equipment of integrated coal mining working face by far. Considering the irreplaceable status of scraper conveyor, improving its production technology becomes the only method to improve the working environment. The rapid development of computer technology makes the finite element method use widely in the field of noise reduction research (XIE, X.C. \& LI, X.H. 2012). But due to the particularity of the working environment and the complexity of the load, researchers often use the finite element method of modal analysis simply and efficiently to predict the vibration and noise of the transmission. In this paper, based on a certain type of central single chain scraper conveyor as the research object, the geometric model was established by using Pro/e software and then the modal analysis of the three main parts of scraper conveyor transmission system was completed with the finite element analysis software ANSYS. Finally, the natural frequencies and mode shapes of the first twenty orders of each component were worked out. On the basis of

\footnotetext{
*Corresponding Author: E-mail: suyu@ sues.edu.cn (Y. SU).

Foundation Item: Item Sponsored by National Natural Science Foundation of China (051301105); Shanghai Leading Academic Discipline Project of China (2013td09)
} 
analysis results, structure improvement scheme was put forward, and then the correctness of the scheme was verified by modal analysis.

\section{MODAL CHARACTERISTICS ANALYSIS OF SCRAPER CONVEYOR}

\subsection{Establishment of the finite element models}

The main components of the scraper conveyor drive system are the scraper, the chute and the round link chain. So, when establishing the geometrical model of the components by Pro/e software, the model need to be simplified according to the simplified conditions, highlighting the focus of the analysis and ignoring the secondary factors. The model's accuracy would be ensured and the computational efficiency also should be taken into account at the same time. The sizes of the components were according to the coal industry standard MT/T152-1997. The models were imported in ANSYS through the connection port of Pro/e software and ANSYS software and then material properties of the three main components were defined with the software ANSYS as shown in Table 1. In order to reduce the analytical errors, 10 nodes tetrahedron three-dimensional finite element (solid 92) was selected to mesh the geometric models intelligently. The results are as Table 2 and the finite element models are as Figure1.
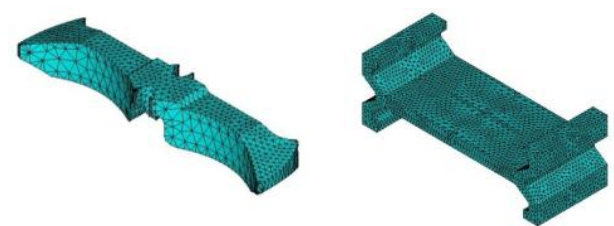

(a) Finite element model of scraper (b) Finite element of chute

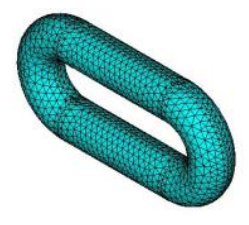

(c) Finite element of round link chain
Figure 1. Finite Element Models of the Main Components of Scraper Conveyer

Table 1 Material Properties

\begin{tabular}{|c|c|c|c|}
\hline & $\begin{array}{c}\text { Modulus of } \\
\text { Elasticity/GPa }\end{array}$ & $\begin{array}{c}\text { Poisson's } \\
\text { Ratio }\end{array}$ & Density $/ \mathrm{g}^{\cdot \mathrm{cm}^{-3}}$ \\
\hline Scraper & 206 & 0.3 & 7.81 \\
\hline Chute & 212 & 0.31 & 7.85 \\
\hline Chain & 206 & 0.3 & 7.80 \\
\hline
\end{tabular}

Table 2 Meshing Results of the Main Components

\begin{tabular}{|c|c|c|c|c|}
\hline & Size/mm & Grade & $\begin{array}{c}\text { Number of } \\
\text { Elements }\end{array}$ & $\begin{array}{c}\text { Number of } \\
\text { Notes }\end{array}$ \\
\hline Scraper & 10 & 10 & 11281 & 18853 \\
\hline Chute & 10 & 10 & 43183 & 67692 \\
\hline Chain & 2 & 10 & 32705 & 47599 \\
\hline
\end{tabular}

\subsection{Results and analysis of the finite element simulation}

According to the vibration theory, a linear vibration system, when it is for free resonance of itself on a certain order natural frequency, has the definite vibration form which is referred to as the mode shape or the modal. The vector describing the vibration form is called the vibration modal vector or the modal vector. The so-called modal orthogonality of modal vector is a very important characteristic. The vibration modal analysis method is based on the inherent modal orthogonality of modal system, and the modal matrix of every-step modal vector is used as the transformation matrix. Linear transformation is done with the physical coordinates. The vibration system that described by physical coordinates and physical parameters could get a set of independent equations. Each equation contains only one independent modal coordinate. The independent equation in modal coordinates and modal parameters is known as the modal equation. Essentially, the purpose of the modal analysis is to remove the coupling of equations and be convenient to get the solutions of problems. Researchers could get the natural frequencies and mode shapes of mechanical components with modal analysis (CAI, H.M. 2013, TIAN, H.T. 2008).

In modal analysis, the only effective load is zero displacement constraint. If a non-zero displacement constraint is applied in a certain degree of freedom (DOF), the program will replace it with the zero displacement constraint. Therefore, when applying the boundary conditions, only the zero displacement constraints are considered, regardless of the other loads. In this paper, Block Lanczos modal extraction method was used for modal expansion of each component, and drew the first twenty orders natural frequencies and mode shapes of each part.

Figure. 2 shows the contrast of the first twenty orders natural frequencies of the main components. Generally, the weighting coefficient of high-order models is smaller than low-order models (TIAN, H.T. 2008). The low-order models were superposed to achieve enough analysis precision. But the Figure.2 shows that the first six orders natural frequencies of the round link chain and the scraper were zero or near zero. It revealed that the component had more than one independent rigid motion under the free modal system. The free frequencies of the translational motion and rotational motion of three directions were zero. It may be more than one zero frequency in theory for a vibration system when it was a semi-definite system. The natural frequencies of chute were not zero under constraint modal. 


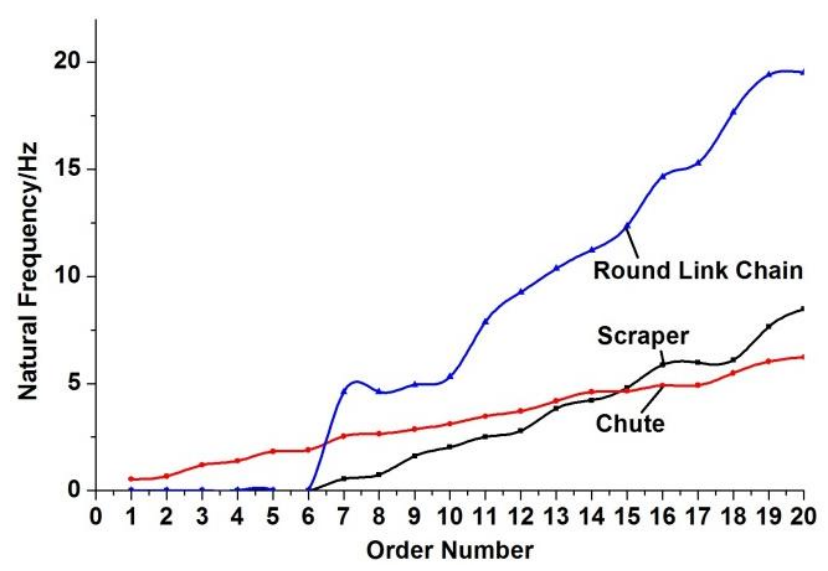

Figure 2. Contrast of Natural Frequencies of the Main Components

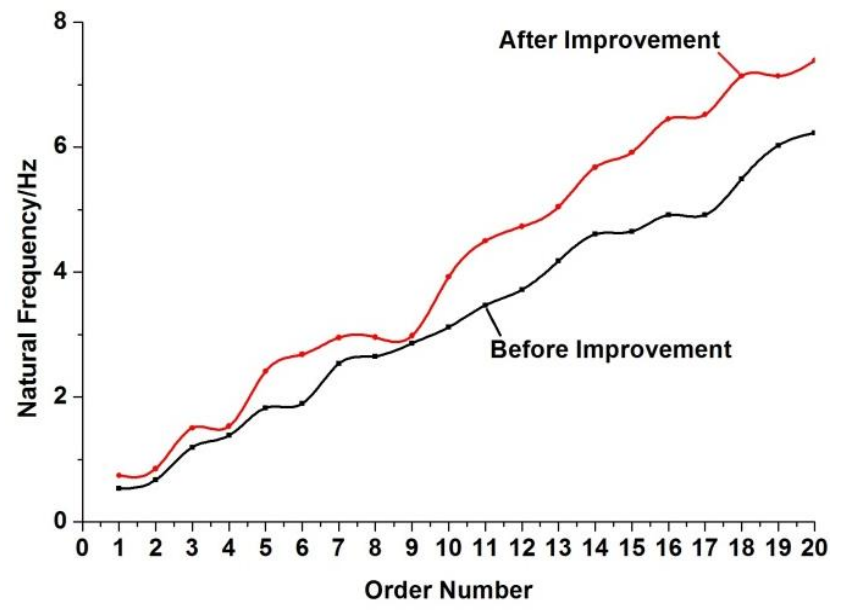

Figure 3. Contrast of Natural Frequencies of the Chute Before and After Improvement

According to the comparison of Figure 2, from the point of growth rate, the growth rates of scraper and round link chain under the free mode were different. The growth rate of natural frequencies of scraper was slow without exploding stage; the growth rate of natural frequencies of round link chain was the fastest between the $6^{\text {th }}$ order and the $7^{\text {th }}$ order and remained big growth rate later. The natural frequency values of the $6^{\text {th }}$ and the $7^{\text {th }}$ order of the chute and round link chain were equal. It indicated that the chute and round link chain had possibility to produce resonance. But because they don't contact with each other, they would not resonate in this order. From the $13^{\text {th }}$ order, the natural frequencies of scraper and chute were approaching. The $15^{\text {th }}$ order natural frequency values were equal. This indicated that resonance could be produced by the scraper and the chute in the $15^{\text {th }}$ order. The natural frequencies of chute and scraper are no longer equal since the $16^{\text {th }}$ order.

According to the above analysis, the resonance of scraper and chute in the $15^{\text {th }}$ order is the main cause of noise pollution of scraper conveyor. Avoiding the resonance is the only way to reduce the vibration noise. Due to the natural frequency is the inherent attribute of components, the natural frequencies of related components can be changed only by changing the material, quality and structure. In order to achieve the purpose of reducing vibration noise, technical improvements of the structure of scraper transmission system could be put forward.

\section{IMPROVEMENT AND VERIFICATION}

In the actual production of the scraper conveyor components, round link chains are designed and manufactured according to the national standards, and the sizes of scraper are according to its corresponding industry standards as well. So improving the structure of the chute has become the only and most effective method. The thickness of central plate was increased as well as both sides of the groove edge of chute in order to improve the dynamic stiffness of the chute and change its natural frequencies. And $10 \mathrm{~mm}$ fillets at the edge of the slot were applied to minimize the strain values. This kind of low noise design method to reduce the noise of the scraper conveyor could meet the purpose of damping noise reduction at the lowest cost and investment.

According to the improvement program, the Pro/e geometric model of chute was established. The model was imported in ANSYS and meshed by the finite element of solid 92. The natural frequencies and mode shapes of the first twenty orders of improved chute were achieved by the modal analysis.

Figure 3 shows the contrast of the first twenty orders natural frequencies of the chute before and after improvement. It revealed that natural frequencies of the chute were close between the $9^{\text {th }}$ order before and after the improvement, but the natural frequencies of chute after the improvement were increased overall. Figure 4 shows the contrast of the natural frequencies of the chute, scraper and round link chain. According to the results, the natural frequencies of the chute and scraper will still be coincidence after the improvement, but the order of coincidence had improved from the $15^{\text {th }}$ order to the $19^{\text {th }}$ order. This suggested that both the order number of resonance and the natural frequency were increased. The improvement scheme had avoided the resonance of the scraper and chute at low-order. Because the values of high-order natural frequencies were bigger than the values of low-order, the scraper conveyor could not meet the high-order frequency in actual work, so the probability of resonance was decreased than original design. 


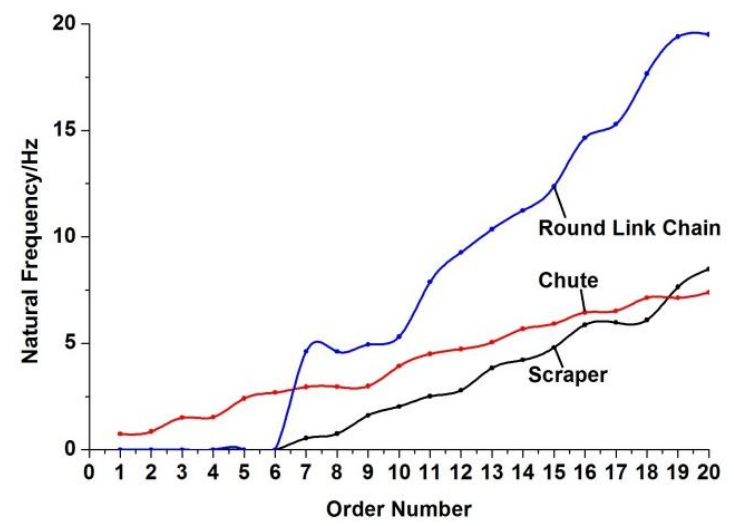

Figure 4. Contrast of Natural Frequencies of the Main Components After Improvement

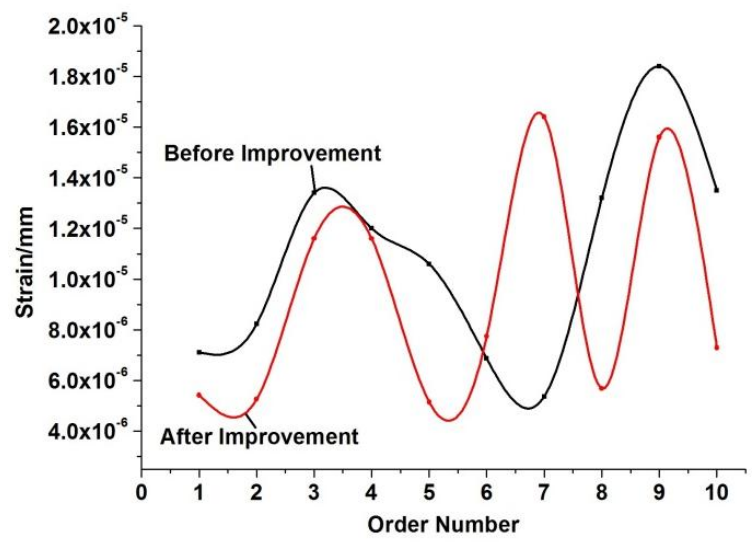

Figure 5. Contrast of Strains of the Chute Before and After Improvement

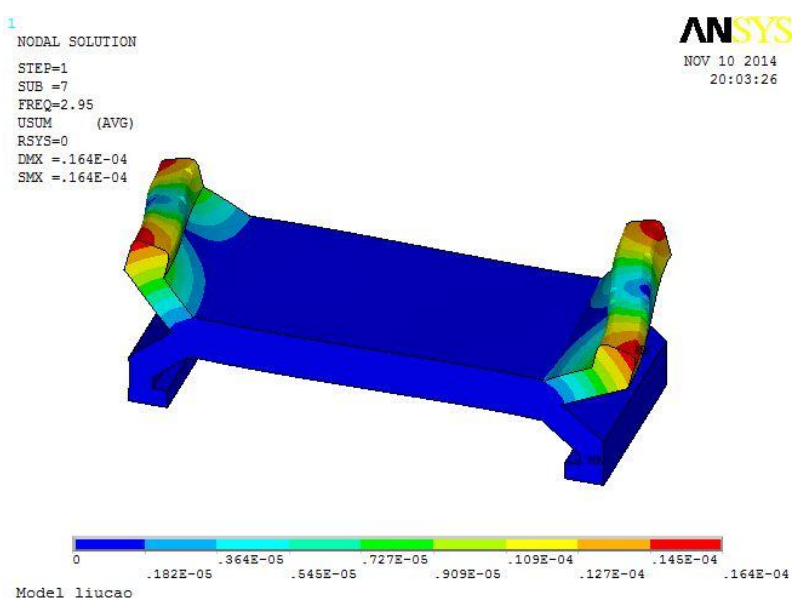

Figure 6 . The $7^{\text {th }}$ Order Mode shape of Improved Chute

According to the results of the modal analysis, the first ten orders strain values of chute before and after improvements were contrasted. Figure 5 shows the results of contrastive analysis. The analysis results indicate that the changing rate of the strain values of chute remained unchanged basically. The strain values were significantly reduced except the $7^{\text {th }}$ order. Although the strain value of the $7^{\text {th }}$ order has changed a lot, the position of the big strain value lied in the four apex angles of the chute, according to the analysis in Figure 6, which would not affect the normal operation of scraper conveyor.

\section{CONCLUSIONS}

1) Based on the modal analysis of scraper conveyor transmission system, the first twenty orders natural frequencies and mode shapes were achieved. The scraper and chute would produce resonance in the $15^{\text {th }}$ order. This resonance not only undermined the stability of the scraper conveyor drive system but also became the main cause of noise pollution when the scraper conveyor was running.

2) After the structural improvement of chute, the vibration modal characteristics of improved chute were analyzed. The values of resonance frequency and the resonated order number were both improved, and the strains were decreased. This indicates that the purpose of reducing vibration noise had achieved. This reflected the validity of the improved scheme. This method for vibration noise test of mutual coupling components in the mechanical equipment could provide an efficient method to reduce vibration noise.

\section{REFERENCES}

[1] TIAN, H.T. 2008. Analysis and research of vibration noise of disc brake based on ANSYS. Wuhan: Wuhan University of Science.

[2] LIU, G.L. \& WU, K. \& WEI, T. 2011. Finite element analysis of SGZ630 scraper conveyor sprocket. Journal of Coal Mine Machinery 32(11): 98-100.

[3] XIE, X.C. \& LI, X.H. 2012. Mining machinery and equipment (third edition). Xuzhou: China University of Mining Press.

[4] CAI, H.M. 2013. Computer simulation of natural frequency of shearer drum. Journal of Coal Mine Machinery 34(11): 57-58.

[5] ZHANG, H. \& GAO, M.Z. \& WANG, K. 2013. Numerical simulation of finite element analysis of hydraulic support before connecting rod based on ANSYS. Journal of Coal Mine Machinery 34(11): 68-70.

[6] Anelle, M.L. \& Brinker, R. 2013. Modal scaling in the operational modal analysis using a finite element model. International Journal of Mechanical Science 76(5): 256258.

[7] Allahyar, M. \& Javad, P. 2010. New adaptive recursive RLS based fast-array IIR filter for active noise and vibration control systems. Journal of Signal Processing 91(1): 99-113.

[8] CUI, K. \& LIU, H.J. \& WANG, H.J. 2012. Vibration response analysis of SGZ 1000/3 × 1000 chain wheel. Journal of Coal Mine Machinery 34(9): 113-115.

[9] LI, G.P. \& ZHANG, J.X. 2010. Finite element analysis of vibration and noise of SCB dry type transformer. Journal of Electric Power 25(6): 487-489.

[10] CAI, H.M. 2013. Computer simulation of natural frequency of shearer drum. Journal of Coal Mine Machinery 34(11): 57-58.

[11] PEI, Z.A. \& WANG, R.J. 2007. Failure analysis and improvement of chute of coal mining scraper conveyer. Journal of Coal Mine Machinery 28(3): 132-134. 